\title{
Baixa Estatura por Haploinsuficiência do Gene SHOX: do Diagnóstico ao Tratamento
}

\begin{abstract}
RESUMO
Estudos realizados em pacientes portadores de deleções parciais dos cromossomos sexuais permitiram a caracterização do $S H O X$, gene localizado na região pseudoautossômica no braço curto dos cromossomos sexuais, fundamental na determinação da altura normal. A perda de uma cópia deste gene na síndrome de Turner (ST) explica dois terços da baixa estatura observada nesta síndrome. A haploinsuficiência do SHOX é detectada em $77 \%$ dos pacientes com discondrosteose de Leri-Weill, uma forma comum de displasia esquelética de herança autossômica dominante e em $3 \%$ das crianças com baixa estatura idiopática (BEI), tornando os defeitos neste gene a principal causa monogênica de baixa estatura. A medida da altura sentada em relação à altura total ( $Z$ da AS/AT para idade e sexo) é uma forma simples de identificar a desproporção corpórea e, associada ao exame cuidadoso do paciente e de outros membros da família, auxilia na seleção de pacientes para o estudo molecular do SHOX. O uso de hormônio de crescimento (GH) está bem estabelecido na ST e em razão da causa comum da baixa estatura com o de crianças com defeitos isolados do SHOX o tratamento destes pacientes com GH é também proposto. Neste artigo será revisado os aspectos clínicos, moleculares e terapêuticos da haploinsuficiência do SHOX. (Arq Bras Endocrinol Metab 2008; 52/5:765-773)
\end{abstract}

Descritores: Hormônio do crescimento/uso terapêutico; Nanismo/diagnóstico; Nanismo/genética; Insuficiência de crescimento; Genes, Homeobox

\section{SUMMARY}

Short stature caused by SHOX gene haploinsufficiency: from diagnosis to treatment.

Studies involving patients with short stature and partial deletion of sex chromosomes identified SHOX gene in the pseudoautosomal region of the $\mathrm{X}$ and $\mathrm{Y}$ chromosomes. SHOX haploinsufficiency is an important cause of short stature in a diversity of clinical conditions. It explains $2 / 3$ of short stature observed in Turner syndrome (TS) patients. Heterozygous mutations in SHOX are observed in $77 \%$ of patients with Leri-Weill dyschondrosteosis, a common dominant inherited skeletal dysplasia and in $3 \%$ of children with idiopathic short stature, indicating that $\mathrm{SHOX}$ defects are the most frequent monogenetic cause of short stature. The sitting height/height ratio $(\mathrm{SH} / \mathrm{H})$ standard deviation score is a simple way to assess body proportions and together with a careful exam of other family members, effectively selected a group of patients that presented a high frequency of SHOX mutations. Growth hormone treatment of short stature due to TS is well established and considering the common etiology of short stature in patients with isolated defects of SHOX gene, this treatment is also proposed for these patients. Here, we review clinical, molecular and therapeutic aspects of SHOX haploinsufficiency. (Arq Bras Endocrinol Metab 2008; 52/5:765-773)

Keywords: Growth hormone/pharmacology; Growth hormone/therapeutic use; Dwarfism/diagnostic; Dwarfism/genetic; Failure to thrive; Genes homeobox revisão

\author{
Alexander A. L. Jorge \\ MIRIAN Y. NISHI \\ MARIANA F. A. FUNARI \\ SILVIA C. SOUZA \\ IVO J. P. ARNHOLD \\ BERENICE B. MENDONÇA
}

Unidade de Endocrinologia do Desenvolvimento, Laboratório de Hormônios e Genética Molecular LIM/42, Disciplina de Endocrinologia da Faculdade de Medicina da Universidade de São Paulo (FMUSP), SP, Brasil.

Recebido em 24/4/2008

Aceito em 28/4/2008 


\section{INTRODUÇÃO}

$\mathrm{O}$ CRESCIMENTO É UM marcador sensível do estado de saúde da criança, e o desvio em relação ao padrão de normalidade pode ser a primeira manifestação de grande variedade de doenças. Mesmo após intensa investigação clínica e laboratorial, muitas crianças com baixa estatura não apresentam diagnóstico conclusivo, sendo classificadas com baixa estatura idiopática (BEI) ou familiar, dependendo dos indícios de causa hereditária para ela.

Nos últimos anos, vários estudos consolidaram os defeitos do gene SHOX como a principal causa monogênica da baixa estatura. Freqüentemente, este diagnóstico passa despercebido pelo endocrinologista ou pelo pediatra que avalia as crianças com baixa estatura. O diagnóstico de defeitos do SHOX permite estabelecer a causa da baixa estatura, evitando a realização excessiva de exames subsidiários. O diagnóstico permite, também, estabelecer prognóstico adequado para a altura final, indicar tratamento com hormônio de crescimento $(\mathrm{GH})$ e oferecer à família aconselhamento genético. Nesta revisão serão abordados os aspectos clínicos, moleculares, além de recentes aspectos do diagnóstico e tratamento da baixa estatura de crianças com defeitos no gene SHOX.

\section{HISTÓRICO}

Vários estudos contribuíram para a identificação e a localização do gene SHOX. Em 1961, Jacobs e cols. (1) estudaram um grupo de mulheres com amenorréia primária e verificaram que as pacientes com deleção do braço curto do cromossomo X eram baixas, enquanto mulheres com deleção apenas do braço longo desse cromossomo apresentavam estatura normal. Em 1982, Goldman e cols. (2), analisando aspectos clínicos e alterações citogenéticas em pacientes com síndrome de Turner (ST), também encontraram correlação entre as deleções do braço curto do cromossomo X e a baixa estatur. Esses trabalhos iniciais indicavam a existência de um gene localizado no braço curto do cromossomo X com papel importante no desenvolvimento somático. Estudos subseqüentes permitiram reduzir a região crítica do cromossomo $\mathrm{X}$ associada à baixa estatura e mostraram a presença de uma região homóloga no cromossomo Y (3). Esta região é conhecida como região pseudoautossômica 1 (pseudoautosomal region 1 - PARl) dos cromossomos sexuais (Figura 1). Trata-se de uma região de aproximadamente 2,6 Mb que fica na porção distal do braço curto desses cromossomos (Xp e Yp). Durante a meiose masculina, os cromossomos X e Y pareiam pela região homóloga na qual foi demonstrada alta taxa de recombinação gênica, por meio do mecanismo de crossing over (4).

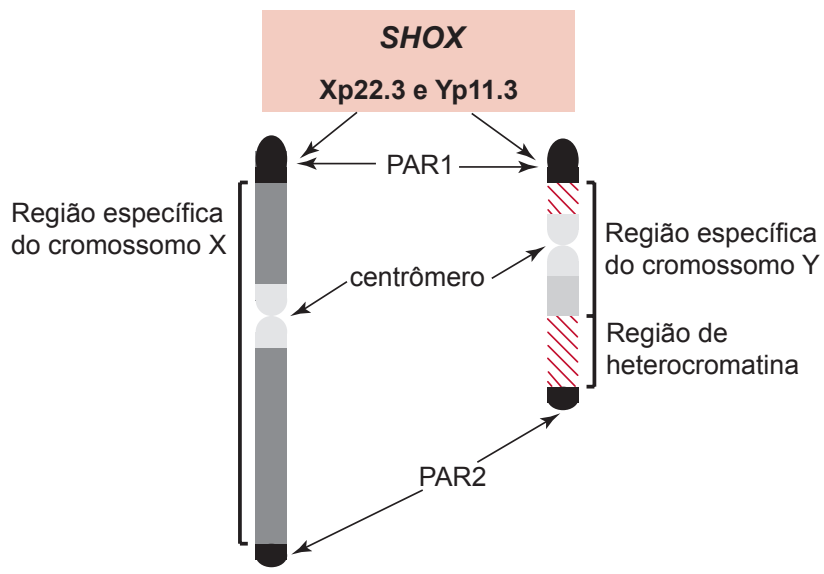

Figura 1. Localização das regiões pseudoautossômicas (PAR) e do gene SHOX nos cromossomos sexuais.

Em 1997, Rao e cols. (5), por meio de estudos de mapeamento de indivíduos com monossomia parcial da PARl, conseguiram restringir a área crítica para a altura a um segmento de apenas $170 \mathrm{~kb}$ e identificaram nessa região um novo gene, que foi denominado $\operatorname{SHOX}$ (stature homeobox containing gene). Além de caracterizar este novo gene, os autores também identificaram mutação missense em heterozigose no $S H O X$ como causa da BEI em uma criança (5).

\section{ORGANIZAÇÃO, EXPRESSÃO, ESTRUTURA E FUNÇÃO DO SHOX}

O SHOX ocupa uma região de aproximadamente 40 kb dentro da PARl (Xp22.3 e Ypll.3) e apresenta 7 éxons (6) (Figura 1). O éxon 1, constituído por 262 pb, não é traduzido. O éxon 2 possui 708 pb e sua porção 5' também não é traduzida. Os éxons 3 e 4 possuem 209 pb e $58 \mathrm{pb}$, respectivamente. O éxon 5 possui 89 pb e os éxons 6a e 6b são constituídos, respectivamente, por $1.166 \mathrm{pb}$ e $625 \mathrm{pb}$, e possuem grande região 3' não traduzida. Há duas classes de 
transcritos, o $S H O X 1$ e o $S H O X 2$, gerados a partir de duas regiões promotoras diferentes (7). O promotor Pl localiza-se a montante do éxon 1 e o promotor P2, no éxon 2. Essas regiões geram RNAms distintos que diferem apenas quanto ao tamanho da região 5 ' não traduzida (5' UTR). O tamanho dessa região é diretamente proporcional à eficiência de tradução do RNAm. Sendo assim, o transcrito SHOXI, por apresentar uma região 5' UTR maior, é mais traduzido. Além destes dois transcritos que diferem na posição 5' UTR, o splicing alternativo dos éxons $6 \mathrm{a}$ e $6 \mathrm{~b}$ resulta dois transcritos: $S H O X a$, com $1870 \mathrm{pb}$, que codifica uma proteína com 292 aminoácidos, e $S H O X b$, com 1349 pb, cuja proteína possui 225 aminoácidos (5). Acredita-se que o SHOXb atue modulando negativamente a ação do SHOXa (8).

O SHOX é altamente expresso nas células osteogênicas, mas sua expressão também foi descrita nos músculos esquelético e cardíaco e nos fibroblastos da medula óssea (9). Durante o período embrionário, sua expressão se restringe aos membros e aos arcos faríngeos, podendo ser detectada nos osteoblastos de embriões humanos a partir do segundo mês de gestação (7). Esses achados sustentam a idéia de que o gene é fundamental para o desenvolvimento ósseo.

O SHOX faz parte de uma família de genes conhecidos como bomeobox gene relacionados com a regulação do desenvolvimento (5). O domínio homeobox é codificado pelos éxons 3 e 4 do SHOX e compreende aproximadamente 60 aminoácidos que desempenha a função de se ligar a seqüências específicas de DNA, atuando como ativador transcricional. Além do homeodomínio, um outro domínio de 14 aminoácidos, denominado OAR e localizado na porção C-terminal, é essencial para manter o potencial de transativação do gene. O transcrito $\mathrm{SHOXb}$, que não apresenta a porção C-terminal inteira, é inativo como fator transcricional $(7,8)$.

A exata função do $S H O X$ ainda não é conhecida. Estudos sugerem que o $S H O X$ atue como repressor da diferenciação dos condrócitos, retardando a fusão das cartilagens de crescimento (9). A haploinsuficiência do SHOX resulta a diferenciação prematura dos condrócitos, acelerando a fusão da cartilagem epifisária e resultando a parada prematura do crescimento (9). Também é sugerido que o $S H O X$ atue na organização colunar das células em proliferação na cartilagem de crescimento $(10)$.

\section{FENÓTIPOS ASSOCIADOS A ALTERAÇÕES DO SHOX}

Duas cópias funcionantes do $S H O X$ são fundamentais para o crescimento normal. Tanto a diminuição (5) quanto o aumento (11) no número de cópias funcionantes do SHOX causam alterações significantes do crescimento.

\section{Mutações com perda de função do SHOX}

A perda de uma das cópias do $S H O X$, ou seja, sua hemizigose, é responsável por dois terços da baixa estatura observada nas pacientes com ST (12), porém a falência ovariana e os outros aspectos dismórficos e malformações observadas em pacientes com ST são causadas pela perda de outras regiões do cromossomo sexual. Os pacientes com mutações de ponto ou deleções do SHOX ou das regiões que regulam a sua expressão, em heterozigose, apresentam fenótipos que variam da discondrosteose de Leri-Weill (DLW) à BEI causados pela haploinsuficiência deste gene. Já a perda das duas cópias do SHOX acarreta displasia esquelética grave, conhecida como displasia mesomélica de Langer (13).

\section{DISCONDROSTEOSE DE LERI-WEILL (DLW)}

A DLW é uma forma freqüente (freqüência estimada de 1:2.000 a 1:4.000) de displasia óssea com herança autossômica dominante, caracterizada por baixa estatura desproporcional, encurtamento mesomélico dos membros (encurtamento do segmento médio das extremidades: perna e antebraço), limitação da movimentação nas articulações do cotovelo e do punho e deformidade típica do antebraço, denominada deformidade de Madelung (pseudoluxação dorsal da porção distal da ulna) (Figura 2) (14,15). Na radiografia de mãos e punhos para determinação da idade óssea é possível observar nas crianças com DLW triangularização da epífise distal do rádio com fusão precoce da sua porção ulnar $(88 \%)$, piramidalização do carpo $(88 \%)$ e transparência da borda ulnar do rádio $(50 \%)(16)$. Também pode-se observar a presença do quarto metacarpo curto e arqueamento do antebraço com desvio ulnar do rádio. A deformidade de Madelung apresenta amplo espectro de apresentação clínica, que pode variar dentro de uma mesma família com penetrância de $50 \%$, sendo geralmente pouco evidente na infância, acentuando-se na adolescência e tendendo a ser mais grave no sexo feminino (17). 
A

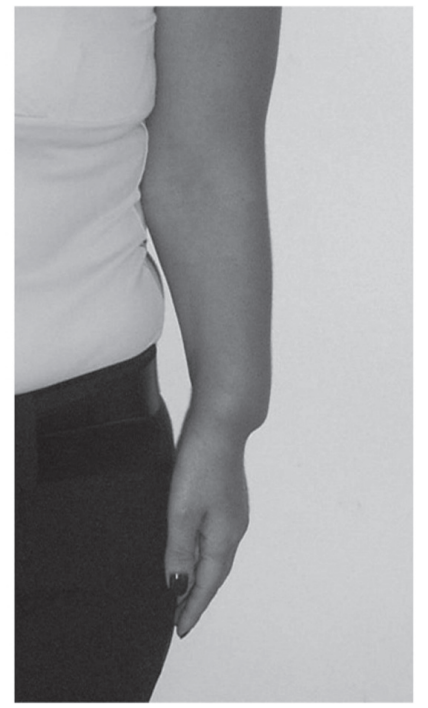

B

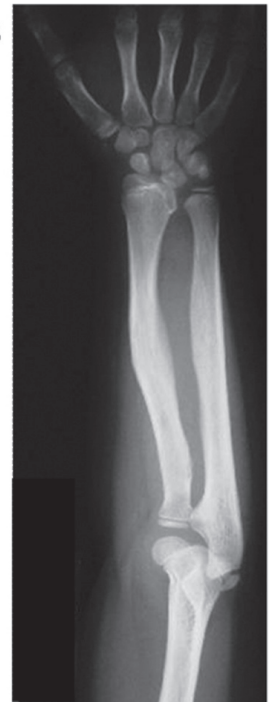

Figura 2. Deformidade de Madelung. A) encurtamento do antebraço com pseudoluxação dorsal da porção distal da ulna; B) radiografia de antebraço e punho com desvio ulnar do rádio e fusão da borda ulnar do rádio.

Além desses sinais, os pacientes com DLW freqüentemente apresentam palato ogival, micrognatia, cúbito valgo, geno varo, aspecto de musculatura hipertrófica nos membros e tendência a apresentar $\mathrm{Z}$ do índice de massa muscular (IMC) elevado (18). A desproporção corpórea característica da DLW nem sempre é evidente ao exame físico, necessitando da medida dos segmentos corpóreos para seu reconhecimento.

As medidas úteis para a avaliação das proporções corpóreas incluem a altura em pé e sentada, a envergadura, o púbis-chão e o púbis-vértice. No ambulatório, tem-se utilizado, por sua maior precisão, a relação da altura sentada/altura total avaliada em relação à idade cronológica e ao sexo ( $\mathrm{Z}$ da AS/AT) (19). A altura sentada pode ser obtida utilizando estadiômetro apropriado ou adaptando uma caixa removível (com $60 \mathrm{~cm}$ de altura) a um estadiômetro (Figura 3). A presença de Z da AS $/ \mathrm{ST}>+2$ indica baixa estatura desproporcional por comprometimento do crescimento dos membros. Os gráficos normativos para avaliação da relação AS/AT podem ser encontrados em www.growthanalyser.org.

A análise desta relação em famílias acompanhadas em nosso serviço mostrou média de $\mathrm{Z}$ da AS /AT +3,2 $\pm 0,9$ em pacientes com DLW. O Z da AS/AT encontrava-se alterado mesmo em pacientes com altura dentro da normalidade ou sem a deformidade de $\mathrm{Ma}$ delung, mas com o mesmo defeito molecular do caso

index com DLW. A gravidade da baixa estatura pode variar consideravelmente mesmo dentro da mesma família ( $\mathrm{Z}$ da altura de $-1,2$ a $-3,6)(17)$. A altura média de pacientes com DLW encontra-se entre 2 a 3 desvios-padrão (DP) abaixo da média para idade e sexo $(12,17,18)$. A presença de altura dentro da normalidade na infância, muitas vezes observada em filhos de pacientes afetados, não assegura altura adulta adequada e ausência de DLW posteriormente, pois na puberdade estas crianças podem apresentar rápido avanço da idade óssea, ocasionando parada precoce do crescimento e resultando altura adulta abaixo da normal $(14,17)$.

Dois grupos independentes descreveram famílias com DLW com defeitos em heterozigose no SHOX: microdeleções da PARl compreendendo o SHOX ou mutações de ponto neste gene $(13,20)$. Aproximadamente, $77 \%$ (56\% a $100 \%)$ dos pacientes com discondrosteose apresentam mutações ou deleções do gene $\operatorname{SHOX}(13,15,20,21)$ (Tabela 1). Novos defeitos moleculares, como a deleção de regiões distais ao $S H O X$ e que regulam positivamente a sua expressão, foram recentemente descritos como causa da DLW em pacientes com o gene $S H O X$ íntegro $(28,29)$.
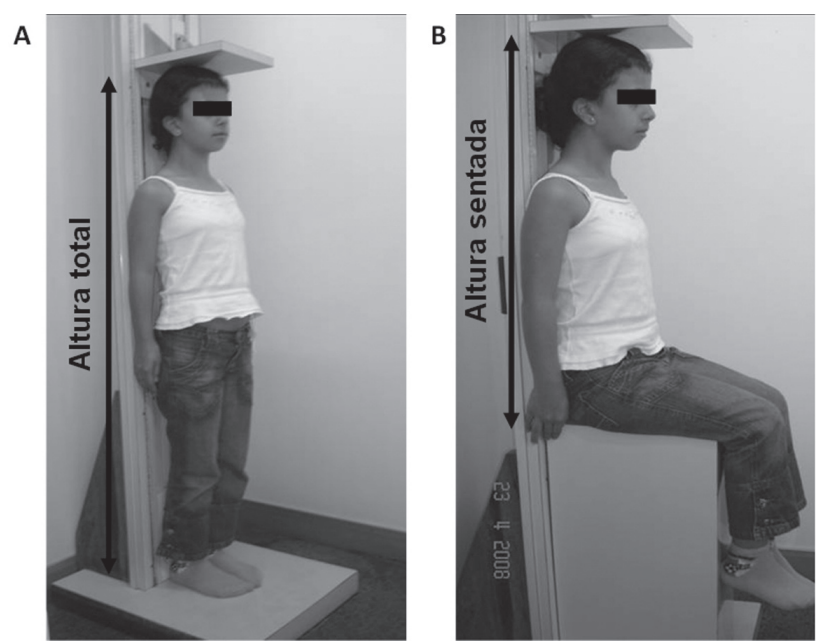

Figura 3. Criança sendo medida de pé (A) e sentada (B) em estadiômetro. A altura sentada foi obtida utilizando estadiômetro e adaptando uma caixa removivel de madeira com $60 \mathrm{~cm}$ de altura e base de $25 \times 30 \mathrm{~cm}$, colocada com o estadiômetro. O paciente deve ser medido com a coluna colada ao estadiômetro, mantendo o tronco em um ângulo reto em relação às coxas e estas em relação às pernas. 
Tabela 1. Freqüência de alterações do SHOX em pacientes com discondrosteose de Leri-Weill e BEI.

\begin{tabular}{|c|c|c|c|}
\hline \multirow[t]{2}{*}{ Autor/ano } & \multicolumn{2}{|c|}{$\mathrm{N}^{\circ}$ de afetados $/ \mathrm{n}^{\circ}$ total estudado } & \multirow{2}{*}{$\begin{array}{l}\text { Freqüência } \\
\text { de mutações }\end{array}$} \\
\hline & Deleçōes & Mutaçōes de ponto & \\
\hline \multicolumn{4}{|c|}{ Pacientes com baixa estatura idiopática } \\
\hline Rao e cols., 1997 (5) & $0 / 91$ & $1 / 91$ & $1,1 \%$ \\
\hline Binder, Schwarze e Ranke, 2000 (22) & $1 / 68$ & $0 / 68$ & $1,5 \%$ \\
\hline Stuppia e cols., 2003 (23) & $4 / 56$ & $3 / 56$ & $12,5 \%$ \\
\hline Huber e cols., 2006 (24) & $8 / 78$ & $4 / 78$ & $15 \%$ \\
\hline Jorge e cols., 2007 (17) & $0 / 63$ & $2 / 63$ & $3,2 \%$ \\
\hline Rappold e cols., 2007 (18) & $25 / 1534$ & $9 / 1534$ & $2,2 \%$ \\
\hline \multicolumn{4}{|c|}{ Pacientes com discondrosteose de Leri-Weill } \\
\hline Belin e cols., 1998 (13) & $7 / 8$ & $1 / 8$ & $100 \%$ \\
\hline Shears e cols., 1998 (20) & $6 / 7$ & $1 / 7$ & $100 \%$ \\
\hline Schiller e cols., 2000 (21) & $10 / 18$ & $0 / 18$ & $56 \%$ \\
\hline Ross e cols., 2001 (15) & $4 / 21$ & $17 / 21$ & $100 \%$ \\
\hline Grigelioniene e cols., 2001 (25) & $16 / 28$ & $6 / 28$ & $79 \%$ \\
\hline Falcinelli e cols., 2002 (26) & $10 / 21$ & $3 / 21$ & $62 \%$ \\
\hline Flanagan e cols., 2002 (27) & $9 / 18$ & $3 / 18$ & $67 \%$ \\
\hline Binder e cols., 2004 (12) & $7 / 20$ & $7 / 20$ & $70 \%$ \\
\hline Huber e cols., 2006 (24) & $35 / 62$ & $7 / 62$ & $68 \%$ \\
\hline Jorge e cols., 2007 (17) & $8 / 9$ & $0 / 9$ & $89 \%$ \\
\hline Rappold e cols., 2007 (18) & $25 / 55$ & $7 / 55$ & $58 \%$ \\
\hline
\end{tabular}

\section{DEFEITOS DO SHOX EM PACIENTES COM BEI}

Alterações no SHOX também têm sido descritas em indivíduos classificados como portadores de BEI. No estudo inicial de Rao e cols. (5), foi descrita uma mutação nonsense (R195X) em um de 91 ( $1,1 \%)$ pacientes com BEI. Posteriormente, essa mesma mutação foi encontrada em um paciente com discondrosteose (20). Os estudos subseqüentes demonstraram freqüência de mutações do $S H O X$ de $1,1 \%$ a $3,2 \%$ em crianças com BEI $(16,17,27)$. Dois estudos que avaliaram o SHOX em crianças com BEI encontraram freqüência inexplicavelmente alta de mutações neste gene $(12,5 \%$ e $14 \%)$ $(23,24)$. Porém, um estudo recente, que avaliou o SHOX em 1.534 crianças com BEI não selecionadas por apresentarem desproporções corpóreas, encontrou freqüência de alterações neste gene de 2,2\% (18), compatível com a maioria dos estudos na literatura (Tabela 1 ). Entretanto, nosso estudo mostrou que a seleção de crianças com BEI para o estudo molecular por meio da presença de desproporção corpórea ( $\mathrm{Z}$ da AS $/ \mathrm{AT}>+2)$ aumentou a freqüência de alterações do $S H O X$ de $3,2 \%$ para $22 \%(17)$.

\section{DETECÇÃO DAS ALTERAÇÕES DO SHOX}

O estudo molecular do SHOX visa a identificar deleções e mutações de ponto neste gene, permitindo a confirmação diagnóstica, orientação genética e diagnóstico precoce em crianças de famílias acometidas por DLW ou por BEI. O estudo molecular do SHOX está indicado em famílias com DLW ou em crianças com BEI com Z da AS/AT > +2.

Há várias metodologias que permitem a detecção de alterações do $S H O X$. Grandes deleções podem ser detectadas por estudos de citogenética tradicional. A análise do cariótipo com bandamento $\mathrm{G}$ em cromossomos metafásicos, obtidos por meio de cultura de linfócitos, permite a visualização de perdas de grandes porções cromossômicas, como as que ocorrem nas monossomias parciais ou totais do X, características da ST. 
A hibridação in situ com fluorescência (fluorescence in situ hybridization - FISH) utiliza sondas específicas para o gene de interesse e permite a detecção de microdeleções do cromossomo. Essas sondas, complementares ao $S H O X$, são marcadas com fluorocromo e visualizadas ao microscópio de fluorescência. Em um indivíduo normal, que apresenta duas cópias do $S H O X$, dois sinais fluorescentes são detectados, um em cada cromossomo sexual. Na presença de deleção de uma das cópias do gene, visualiza-se apenas um sinal em cada metáfase ( $\mathrm{Fi}^{-}$ gura 4). A técnica de FISH é uma metodologia trabalhosa e de alto custo. O FISH não possibilita a detecção de mutações de ponto, que levam à troca de aminoácidos, nem de pequenas deleções do SHOX. Nestes casos, a sonda pode hibridar com o segmento remanescente do gene, resultando sinal falso-positivo.

Alterações menores como essas podem ser detectadas com a utilização de técnicas de biologia molecular. O estudo de microssatélites é capaz de detectar pequenas deleções. Essa metodologia utiliza primers marcados com fluorescência para a reação de amplificação por PCR e a análise é realizada em um seqüenciador automático. Ocasionalmente, é necessário o estudo dos progenitores, que nem sempre estão disponíveis, para diferenciar os indivíduos homozigotos, com dois alelos iguais, dos hemizigotos, que apresentam perda de um dos alelos (Figura 5). Em alguns casos, o estudo de microssatélites não é informativo. Quando, por exem- plo, o paciente possui apenas um alelo de determinado marcador e seus pais apresentam o mesmo alelo. Nesse caso, não é possível dizer se o paciente é homozigoto para esse marcador, ou se apresenta a deleção de um dos alelos. No caso do SHOX, por se tratar de um gene relativamente grande, a análise de mais de um marcador é fundamental.

$\mathrm{Na}$ ausência de deleção do $S H O X$ está indicado o seqüenciamento dos éxons do gene para detecção de mutações. Essa metodologia possibilita a detecção de qualquer perda ou troca de nucleotídeo. Apesar de essas técnicas disponíveis, alguns indivíduos com DLW não apresentam alteração no $S H O X$. Nestes casos, podem estar presentes mutações em regiões promotoras ou reguladoras deste gene, assim como mutações intrônicas ou em genes ainda não identificados que desempenham papel semelhante ao do SHOX no desenvolvimento ósseo.

\section{TRATAMENTO DA BAIXA ESTATURA EM PACIENTES COM HAPLOINSUFICIÊNCIA DO SHOX}

\section{Tratamento com hrGH}

Os pacientes com DLW ou BEI, que mostram haploinsuficiência do gene $S H O X$ por mutação de ponto ou deleção, apresentam baixa estatura de causa semelhante à observada nas meninas com ST e, por analogia, pode-
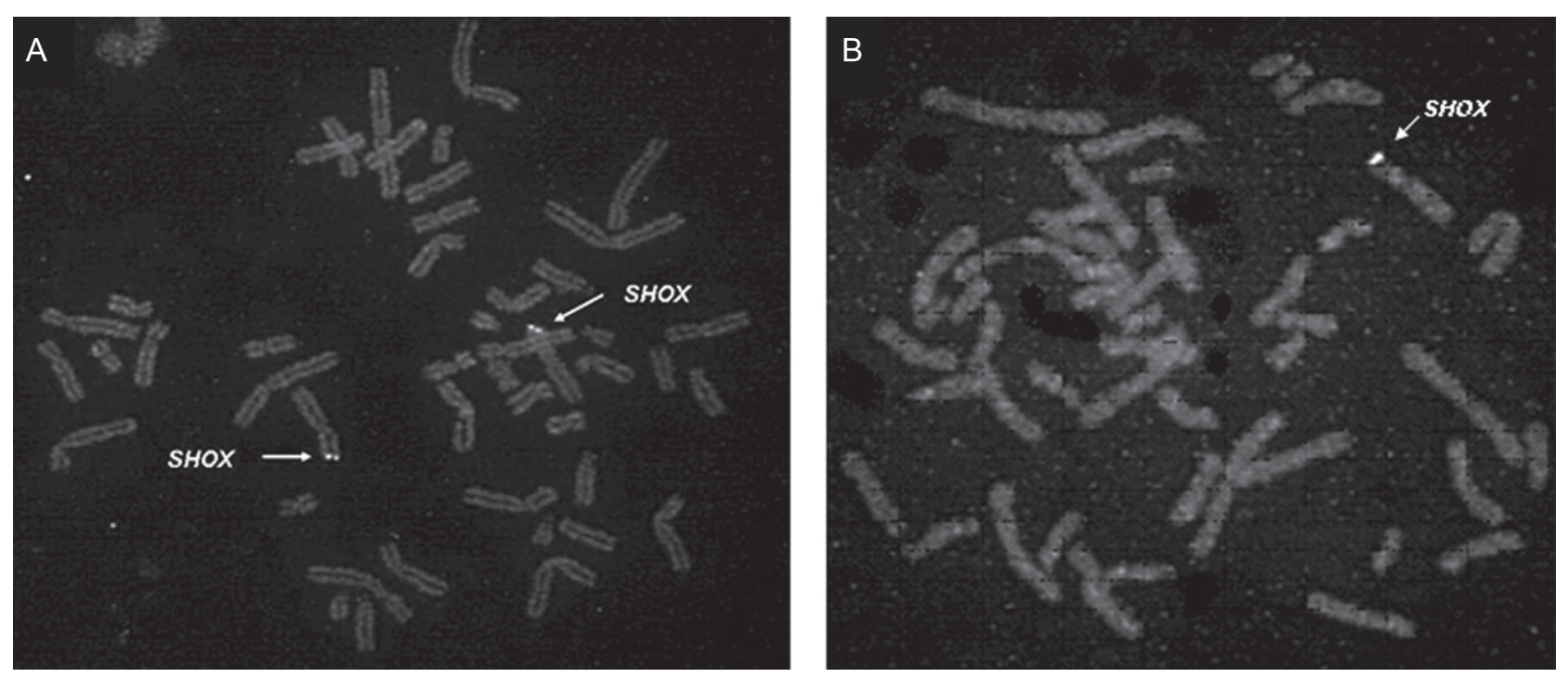

Figura 4. Análise de citogenética por FISH utilizando sonda específica para o gene SHOX. A) cariótipo 46 XX normal; B) cariótipo 46 XX com deleção em heterozigose SHOX. 

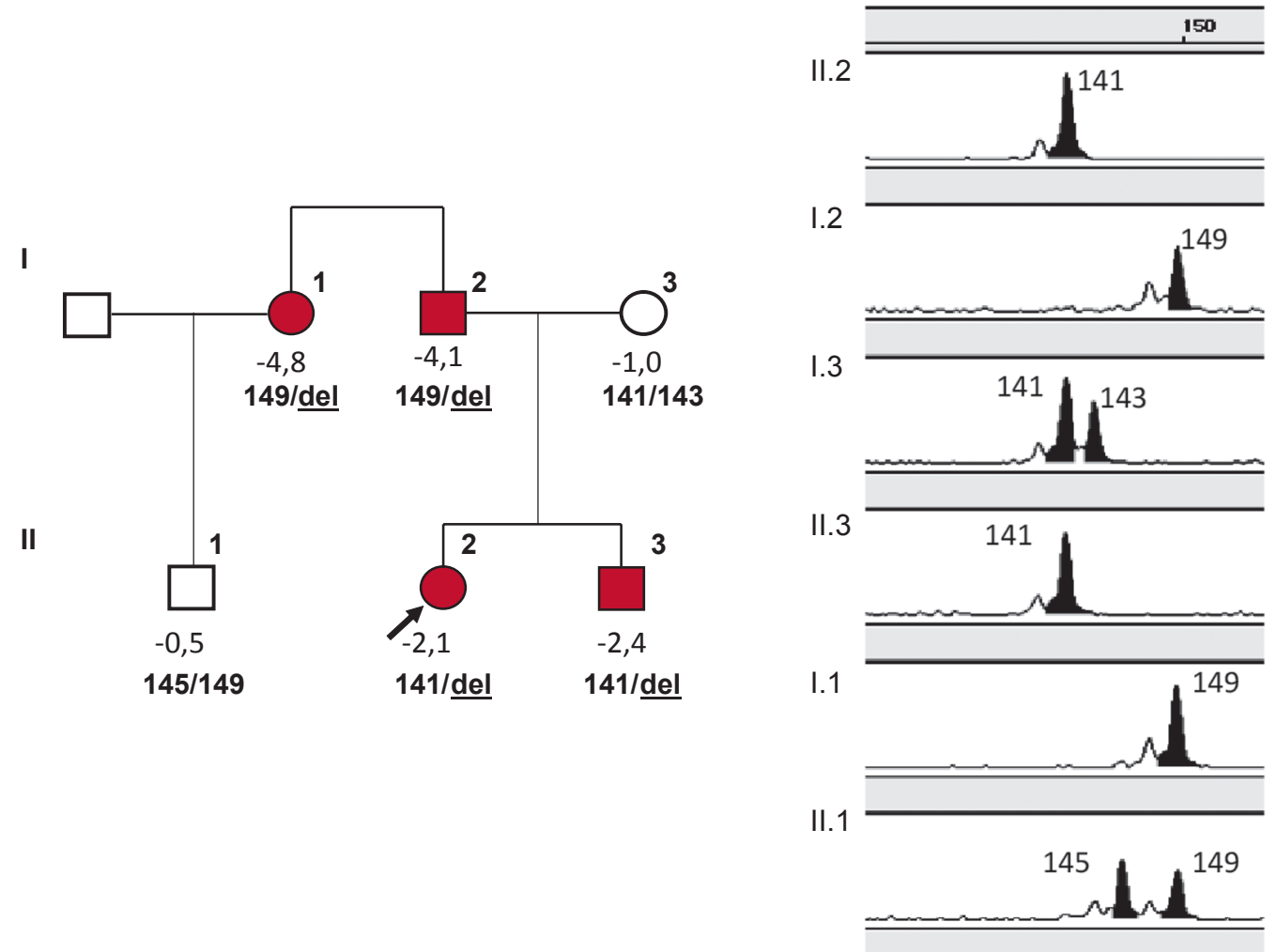

Figura 5. Heredograma e análise do microssatélite de uma família com deleção do gene SHOX. Os indivíduos com deleção do SHOX são representados com símbolos cheios ( ou •). Os números abaixo de cada símbolo representam o Z da altura e o tamanho do fragmento referente ao microssatélite de repetição CA localizado no íntron 2 do gene SHOX. À direita, está representado o resultado de cada indivíduo do produto de amplificação do microssatélite submetido à eletroforese em capilar. Os pacientes afetados apresentam apenas um produto de amplificação (I. 1, I.2, II.2 e II.3), enquanto os indivíduos não afetados apresentam dois produtos de amplificação do microssatélite (l.3 e II. 1), comprovando a monossomia e a dissomia do SHOX, respectivamente.

se supor que apresentariam, de maneira semelhante, os benefícios do uso do hormônio de crescimento recombinante humano (hrGH). Um trabalho recente demonstrou que os pacientes com haploinsuficiência do SHOX mostram resposta de crescimento ao tratamento com hrGH semelhante ao de pacientes com ST e com ganho significante da altura em relação aos pacientes não tratados (30). Os pacientes pré-púberes com haploinsuficiência do gene $S H O X$ e tratados com hrGH na dose de $50 \mu \mathrm{g} / \mathrm{kg} /$ dia (equivalente a $0,15 \mathrm{U} / \mathrm{kg} /$ dia) apresentaram aumento da velocidade de crescimento (VC) $(4,8 \pm 0,3 \mathrm{~cm} /$ ano antes do tratamento, $8,7 \pm 0,3 \mathrm{~cm} /$ ano no primeiro ano e $7,3 \pm 0,2 \mathrm{~cm} /$ ano no segundo ano de tratamento), enquanto pacientes não tratados mantiveram a VC estável nos dois anos de observação (30). Este aumento na VC refletiu em me- lhora no $\mathrm{Z}$ da altura de $-3,3 \pm 0,2$ pré-tratamento para $-2,1 \pm 0,2$ após dois anos de tratamento e ganho médio de $5,9 \mathrm{~cm}$ a mais do que o grupo-controle no mesmo período (30). Os pacientes com fenótipo de DLW e BEI apresentaram resposta semelhante ao tratamento com hrGH (30). Porém, ainda não há dados sobre a altura final de crianças com defeitos do SHOX tratadas com hrGH.

\section{BLOQUEIO PUBERAL COM ANÁLOGOS DO GnRH (aGnRH)}

Crianças com haploinsuficiência do SHOX mostram avanço importante da idade óssea durante a puberdade. Assim sendo, foi proposto que o bloqueio da puberdade com análogos do $\mathrm{GnRH}$ (aGnRH) poderia promo- 
ver maior ganho de altura $(31,32)$. Adicionalmente, a deformidade de Madelung é pouco freqüente em pacientes com ST ( $3 \%$ versus $24 \%$ dos pacientes com haploinsuficiência do SHOX) (18). Acredita-se que a ausência da puberdade dos pacientes com ST seja responsável pela menor incidência da deformidade de Madelung. Dessa forma, alguns pesquisadores sugerem que o uso de aGnRH retardando a puberdade poderia atenuar ou evitar esta deformidade. Porém, ainda não há dados na literatura que comprovem o benefício do tratamento com aGnRH associado ao $\mathrm{GH}$ em crianças com haploinsuficiência do SHOX.

\section{Declaração de conflito de interesse}

Os autores declaram não ter conflito de interesse em relação ao presente artigo.

\section{AGRADECIMENTOS}

Este trabalho obteve apoio da Fundação de Amparo à Pesquisa do Estado de São Paulo (Fapesp): Projeto Temático $\mathrm{n}^{\mathrm{O}}$ 05/04726-0 e do Conselho Nacional de Desenvolvimento Científico e Tecnológico (CnPQ): $\mathrm{n}^{\mathrm{o}}$ 307951/06-5 para A.A.L.J., $\mathrm{n}^{\circ}$ 301246/95-5 para B.B.M. e ${ }^{\circ}$ 300938/06-3 para I.J.P.A.

\section{REFERÊNCIAS}

1. Jacobs PA, Harnden DG, Buckton KE, Brown WM, King MJ, Mc $\mathrm{BJ}$, et al. Cytogenetic studies in primary amenorrhoea. Lancet. 1961;1:1183-9.

2. Goldman B, Polani PE, Daker MG, Angell RR. Clinical and cytogenetic aspects of X-chromosome deletions. Clin Genet. 1982;21:36-52.

3. Fisher EM, Beer-Romero P, Brown LG, Ridley A, McNeil JA, Lawrence JB, et al. Homologous ribosomal protein genes on the human $\mathrm{X}$ and $\mathrm{Y}$ chromosomes: escape from $\mathrm{X}$ inactivation and possible implications for Turner syndrome. Cell. 1990;63:1205-18.

4. Rouyer F, Simmler MC, Johnsson C, Vergnaud G, Cooke HJ Weissenbach J. A gradient of sex linkage in the pseudoautosomal region of the human sex chromosomes. Nature. 1986;319:291-5.

5. Rao E, Weiss B, Fukami M, Rump A, Niesler B, Mertz A, et al. Pseudoautosomal deletions encompassing a novel homeobox gene cause growth failure in idiopathic short stature and Turner syndrome. Nat Genet. 1997;16:54-63.

6. Blaschke RJ, Rappold GA. SHOX: growth, Leri-Weill and Turner syndromes. Trends Endocrinol Metab. 2000;11:227-30.

7. Blaschke RJ, Topfer C, Marchini A, Steinbeisser H, Janssern JW, Rappold GA. Transcriptional and translational regulation of the Leri-Weill and Turner syndrome homeobox gene SHOX. J Biol Chem. 2003;278:47820-6.
8. Rao E, Blaschke RJ, Marchini A, Niesler B, Burnett M, Rappold GA. The Leri-Weill and Turner syndrome homeobox gene SHOX encodes a cell-type specific transcriptional activator. Hum Mol Genet. 2001;10:3083-91.

9. Munns CJ, Haase HR, Crowther LM, Hayes MT, Blaschke R, Rappold G, et al. Expression of SHOX in human fetal and childhood growth plate. J Clin Endocrinol Metab. 2004;89:4130-5.

10. Thomas NS, Maloney V, Bass P, Mulik V, Wellesley D, Castle B. SHOX mutations in a family and a fetus with Langer mesomelic dwarfism. Am J Med Genet. 2004; 128A:179-84.

11. Binder G, Eggermann T, Enders $H$, Ranke MB, Dufke A. Tall stature, gonadal dysgenesis, and stigmata of Turner's syndrome caused by a structurally altered $\mathrm{X}$ chromosome. J Pediatr. 2001;138:285-7.

12. Binder G, Renz A, Martinez A, Keselman A, Hesse V, Riedl SW, et al. SHOX haploinsufficiency and Leri-Weill dyschondrosteosis: prevalence and growth failure in relation to mutation, sex, and degree of wrist deformity. J Clin Endocrinol Metab. 2004;89:4403-8.

13. Belin V, Cusin V, Viot G, Girlich D, Toutain A, Moncla A, et al. SHOX mutations in dyschondrosteosis (Leri-Weill syndrome). Nat Genet. 1998;19:67-9.

14. Kosho T, Muroya K, Nagai T, Fujimoto M, Yokoya S, Sakamoto $\mathrm{H}$, et al. Skeletal features and growth patterns in 14 patients with haploinsufficiency of SHOX: implications for the development of Turner syndrome. J Clin Endocrinol Metab. 1999;84:4613-21.

15. Ross JL, Scott C Jr., Marttila P, Kowal K, Nass A, Papenhausen $P$, et al. Phenotypes associated with SHOX deficiency. J Clin Endocrinol Metab. 2001;86:5674-80.

16. Binder G, Ranke MB, Martin DD. Auxology is a valuable instrument for the clinical diagnosis of SHOX haploinsufficiency in school-age children with unexplained short stature. J Clin Endocrinol Metab. 2003;88:4891-6.

17. Jorge AA, Souza SC, Nishi MY, Billerbeck AE, Liborio DC, Kim $\mathrm{CA}$, et al. SHOX mutations in idiopathic short stature and LeriWeill dyschondrosteosis: frequency and phenotypic variability. Clin Endocrinol (Oxf). 2007;66:130-5.

18. Rappold G, Blum WF, Shavrikova EP, Crowe BJ, Roeth R, Quigley CA, et al. Genotypes and phenotypes in children with short stature: clinical indicators of SHOX haploinsufficiency. J Med Genet. 2007;44:306-13.

19. Gerver WJ, Bruin R. Paediatric morphometrics - a reference manual. $2^{\mathrm{a}}$ ed. Universitaire Pers Maastricht, Maastricht; 2001

20. Shears DJ, Vassal HJ, Goodman FR, Palmer RW, Reardon W, Superti-Furga A, et al. Mutation and deletion of the pseudoautosomal gene SHOX cause Leri-Weill dyschondrosteosis. Nat Genet. 1998;19:70-3.

21. Schiller S, Spranger S, Schechinger B, Fukami M, Merker S, Drop SL, et al. Phenotypic variation and genetic heterogeneity in Leri-Weill syndrome. Eur J Hum Genet. 2000;8:54-62.

22. Binder G, Schwarze CP, Ranke MB. Identification of short stature caused by SHOX defects and therapeutic effect of recombinant human growth hormone. J Clin Endocrinol Metab. 2000;85:245-9.

23. Stuppia L, Calabrese G, Gatta V, Pintor S, Morizio E, Fantasia $\mathrm{D}$, et al. SHOX mutations detected by FISH and direct sequencing in patients with short stature. J Med Genet. 2003;40:E11.

24. Huber C, Rosilio M, Munnich A, Cormier-Daire V. High incidence of SHOX anomalies in individuals with short stature. J Med Genet. 2006; 43:735-9. 
25. Grigelioniene G, Schoumans J, Neumeyer L, Ivarsson A, Eklof $\mathrm{O}$, Enkvist $\mathrm{O}$, et al. Analysis of short stature homeobox-containing gene ( SHOX) and auxological phenotype in dyschondrosteosis and isolated Madelung deformity. Hum Genet. 2001;109:551-8.

26. Falcinelli C, lughetti L, Percesepe A, Calabrese G, Chiarelli F, Cisternino $M$, et al. SHOX point mutations and deletions in Leri-Weill dyschondrosteosis. J Med Genet. 2002;39:E33.

27. Flanagan SF, Munns CF, Hayes M, Williams B, Berry M, Vickers $\mathrm{D}$, et al. Prevalence of mutations in the short stature homeobox containing gene (SHOX) in Madelung deformity of childhood. J Med Genet. 2002;39:758-63.

28. Benito-Sanz S, Thomas NS, Huber C, Gorbenko del Blanco D, Aza-Carmona M, Crolla JA, et al. A novel class of Pseudoautosomal region 1 deletions downstream of SHOX is associated with Leri-Weill dyschondrosteosis. Am J Hum Genet. 2005;77:533-44.

29. Fukami M, Kato F, Tajima T, Yokoya S, Ogata T. Transactivation function of an approximately 800-bp evolutionarily conserved sequence at the SHOX $3^{\prime}$ region: implication for the downstream enhancer. Am J Hum Genet. 2006;78:167-70.
30. Blum WF, Crowe BJ, Quigley CA, Jung H, Cao D, Ross JL, et al. Growth hormone is effective in treatment of short stature associated with short stature homeobox-containing gene deficiency: two-year results of a randomized, controlled, multicenter trial. J Clin Endocrinol Metab. 2007;92:219-28.

31. Fukami M, Nishi Y, Hasegawa Y, Miyoshi Y, Okabe T, Haga N, et al. Statural growth in 31 Japanese patients with SHOX haploinsufficiency: support for a disadvantageous effect of gonadal estrogens. Endocr J. 2004;51:197-200.

32. Ogata T, Onigata K, Hotsubo T, Matsuo N, Rappold G. Growth hormone and gonadotropin-releasing hormone analog therapy in haploinsufficiency of SHOX. Endocr J. 2001;48:317-22.

Endereço para correspondência:

Alexander A. L. Jorge ou Berenice B. Mendonça Hospital das Clínicas, Laboratório de Hormônios Av. Dr. Enéas de Carvalho Aguiar, 155 PAMB, $2^{\circ}$ andar, bloco 6 05403-900 São Paulo, SP

E-mail: alexj@pq.cnpq.br ou beremen@usp.br 